\title{
Characterization of Therapeutic Monoclonal Antibodies at the Subunit-Level using Middle-Down 193 nm Ultraviolet Photodissociation
}

\author{
Victoria C. Cotham and Jennifer S. Brodbelt* \\ Department of Chemistry \\ The University of Texas at Austin \\ Austin, TX, USA 78712
}

Correspondence to: Jennifer Brodbelt, jbrodbelt@.cm.utexas.edu

Supplemental Information: Supplement figures include a workflow diagram, representative chromatograms of mAb subunits, sequence alignment of mAbs, ESI-MS1 spectra of subunits, a bar graph summarizing the sequence coverage per subunit as a function of laser activation parameters, bar graphs comparing the number of positionally unique N-terminal and C-terminal fragment ions and total sequence coverage for adalimumab subunits, and tables summarizing the matched ions obtained by UVPD and two variations of ETD for all subunits. 
Figure S1. Schematic representation of sample preparation and analysis workflow. IgG subunits are first produced from IdeS digestion and TCEP reduction. High resolution LC-MS ${ }^{1}$ analysis using $120 \mathrm{~K}$ resolution (at $\mathrm{m} / \mathrm{z} 400$ ) provides accurate mass measurements of subunits in addition to elution profiles and charge state distributions necessary for targeted MS/MS activation.
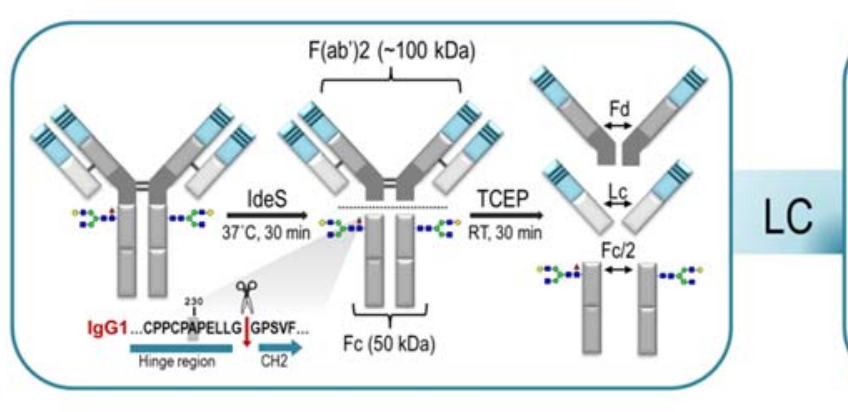

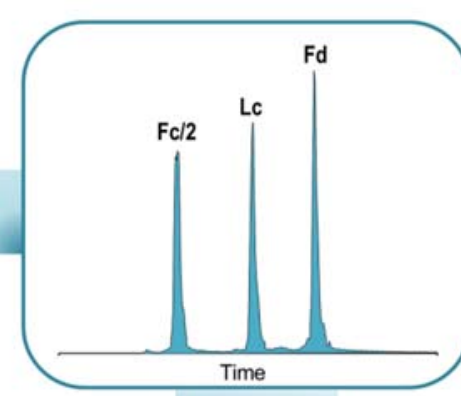

Targeted

Precursor

Selection
Fc/2

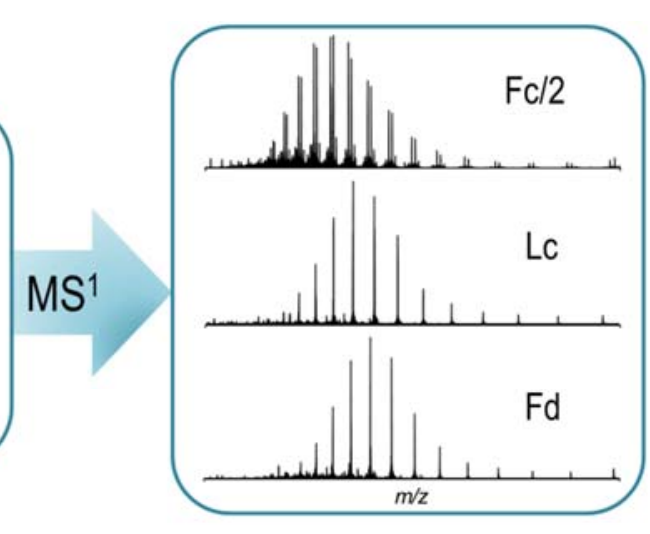

D[I Q]MITIQ]S\PS SILIS A SLV G D R V T I T C R TA

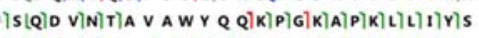

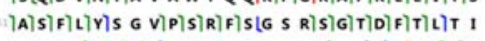

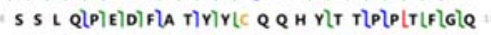

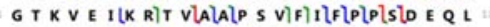

“ KS G T ALS V VLC LLLLIN N FLYLP RLELALK VLQLW K V

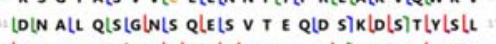

LLS S L T LIS KLALDLYlE LKLHLKLVLYLALCLELVLTIH QLG

LL SLSLPLVLTLKLSLF LN R G E)C C

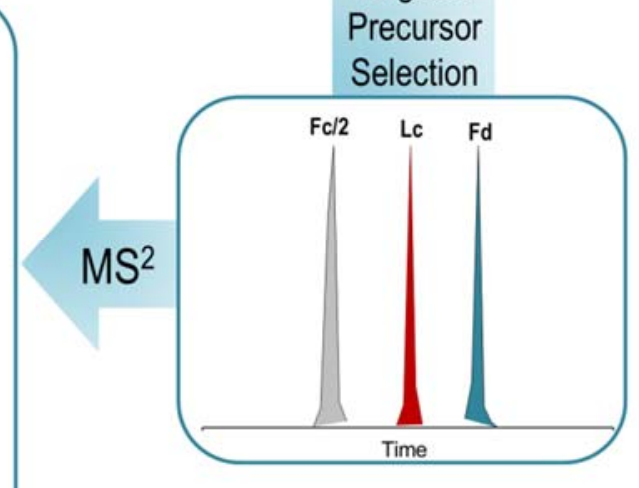


Figure S2. Stacked total ion chromatograms for triplicate LC-MS analyses of IdeS-derived (a) trastuzumab and (b) adalimumab subunits: $\mathrm{Fc} / 2, \mathrm{Lc}$, and $\mathrm{Fd}$, respectively, with baseline chromatographic resolution.

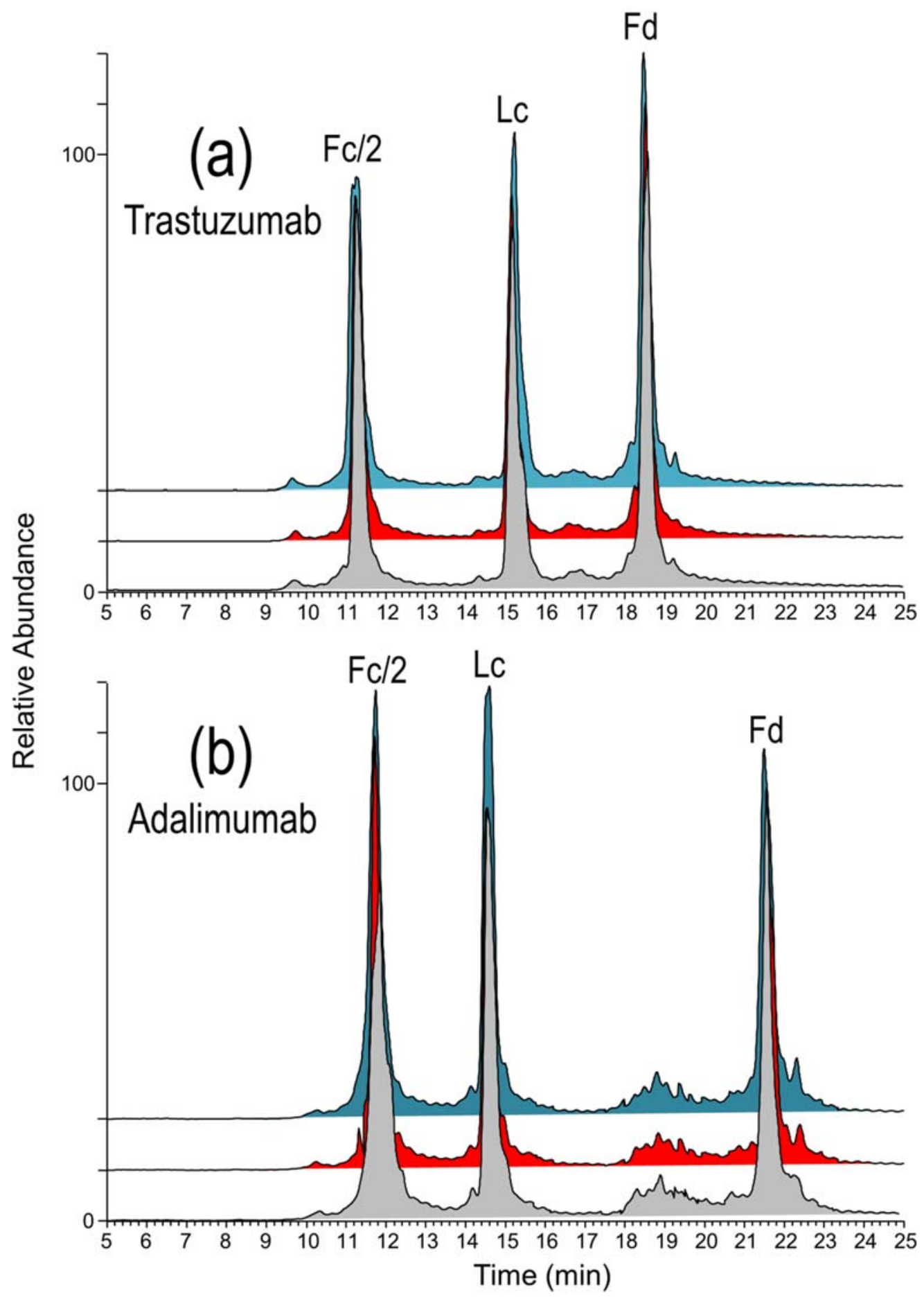


Figure S3. Sequence alignment of trastuzumab and adalimumab $\mathrm{Fc} / 2, \mathrm{Lc}$, and $\mathrm{Fd}$ subunits. Hypervariable CDRs are shown in red.

\section{Fc/2 subunit: $99 \%$ sequence identity}

\begin{tabular}{|c|c|c|c|c|c|c|}
\hline & 10 & 20 & 30 & 40 & 50 & 60 \\
\hline rastu & \multicolumn{6}{|c|}{ GPSVFLFPPKPKDTLMISRTPEVTCVVVDVSHEDPEVKFNWYVDGVEVHNAKTKPREEQY } \\
\hline & \multirow{2}{*}{\multicolumn{6}{|c|}{ 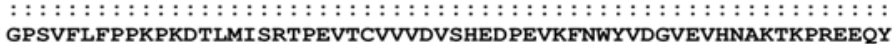 }} \\
\hline \multirow[t]{3}{*}{ Adalim } & & & & & & \\
\hline & 10 & 20 & 30 & 40 & 50 & 60 \\
\hline & 70 & 80 & 90 & 100 & 110 & 120 \\
\hline Trastu & \multicolumn{6}{|c|}{ NSTYRVVSVLTVLHQDWLNGKEYKCKVSNKALPAPIEKTISKAKGQPREPQVYTLPPSRE } \\
\hline & \multirow{2}{*}{\multicolumn{6}{|c|}{$\begin{array}{l}\text { N } \\
\text { NSTYRVVSVLTVLHQDWLNGKEYKCKVSNKALPAPIEKTISKAKGQPREPQVYTLPPSRD }\end{array}$}} \\
\hline Adalim & & & & & & \\
\hline & 70 & 80 & 90 & 100 & 110 & 120 \\
\hline & 130 & 140 & 150 & 160 & 170 & 180 \\
\hline Trastu & \multicolumn{6}{|c|}{ EMTKNQVSLTCLVKGFYPSDIAVEWESNGQPENNYKTTPPVLDSDGSFFLYSKLTVDKSR } \\
\hline & \multicolumn{6}{|c|}{ 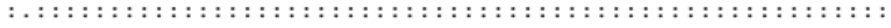 } \\
\hline \multirow[t]{3}{*}{ Adalim } & ELTKNQVSLTC & CPSDI & SNGQP & TTPPV & SFFLY & DKSR \\
\hline & 130 & 140 & 150 & 160 & 170 & 180 \\
\hline & 190 & 200 & 210 & & & \\
\hline Trastu & \multicolumn{6}{|c|}{ WQQGNVFSCSVMHEALHNHYTQKSLSLSPG } \\
\hline & \multirow{2}{*}{\multicolumn{6}{|c|}{$\begin{array}{l}::::::::::::::::::::::::::::::: \\
\text { WQQGNVFSCSVMHEALHNHYTQKSLSLSPG }\end{array}$}} \\
\hline \multirow[t]{2}{*}{ Adalim } & & & & & & \\
\hline & 190 & 200 & 210 & & & \\
\hline
\end{tabular}

Lc subunit: $92 \%$ sequence identity

$10 \quad 20 \quad 30$

$40 \quad 50$

60

Trastu DIQMTQSPSSLSASVGDRVTITCRASQDVNTAVAWYQQKPGKAPKLLIYSASFLYSGVPS

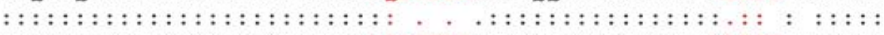
Adalim DIQMTQSPSSLSASVGDRVTITCRASQGIRNYLAWYQQKPGKAPKLLIYAASTLQSGVPS

$\begin{array}{llllll}10 & 20 & 30 & 40 & 50 & 60\end{array}$

$\begin{array}{llllll}70 & 80 & 90 & 100 & 110 & 120\end{array}$

Trastu RFSGSRSGTDFTLTISSLQPEDFATYYCQQHYTTPPTFGQGTKVEIKRTVAAPSVFIFPP

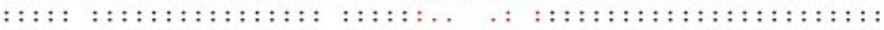

Adalim RFSGSGSGTDFTLTISSLQPEDVATYYCQRYNRAPYTFGQGTKVEIKRTVAAPSVFIFPP

$\begin{array}{llllll}70 & 80 & 90 & 100 & 110 & 120\end{array}$

$\begin{array}{llllll}130 & 140 & 150 & 160 & 170 & 180\end{array}$

Trastu SDEQLKSGTASVVCLLNNFYPREAKVQWKVDNALQSGNSQESVTEQDSKDSTYSLSSTLT $:::::::::::::::::::::::::::::::::::::::::::::::::::::::::::::::$ :

Adalim SDEQLKSGTASVVCLLNNFYPREAKVQWKVDNALQSGNSQESVTEQDSKDSTYSLSSTLT

$\begin{array}{cccccc}130 & 140 & 150 & 160 & 170 & 180 \\ 190 & 200 & 210 & & \end{array}$

Trastu LSKADYEKHKVYACEVTHQGLSSPVTKSFNRGEC

$:::::::::::::::::::::::::::::::::::::::$ :

Adalim LSKADYEKHKVYACEVTHQGLSSPVTKSFNRGEC

$190 \quad 200 \quad 210$

Fd subunit: $86 \%$ sequence identity

10

Trastu EVQLVESGGGLVQPGGSLRLSCAASGFNIKDTYIHWVRQAPGKGLEWVARIYPTNGYTRY

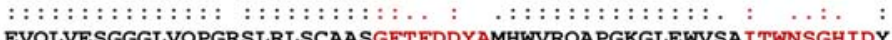

Adalim EVQLVESGGGLVQPGRSLRLSCAASGFTFDDYAMHWVRQAPGKGLEWVSAITWNSGHIDY

$\begin{array}{lllll}10 & 20 & 30 & 40 & 50\end{array}$

$\begin{array}{llll}70 & 80 & 90 & 100\end{array}$

Trastu ADSVKGRFTISADTSKNTAYLQMNSLRAEDTAVYYCSRWGG-DGFYAMDYWGQGTLVTVS

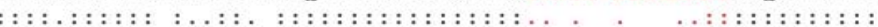

Adalim ADSVEGRFTISRDNAKNSLYLQMNSLRAEDTAVYYCAKVSYLSTASSLDYWGQGTLVTVS

$\begin{array}{ccccccr} & 70 & 80 & 90 & 100 & 110 & 120 \\ 120 & 130 & 140 & 150 & 160 & 170\end{array}$

Trastu SASTKGPSVFPLAPSSKSTSGGTAALGCLVKDYFPEPVTVSWNSGALTSGVHTFPAVLQS $:::::::::::::::::::::::::::::::::::::::::::::::::::::::::::::::::$ :

Adalim SASTKGPSVFPLAPSSKSTSGGTAALGCLVKDYFPEPVTVSWNSGALTSGVHTFPAVLQS

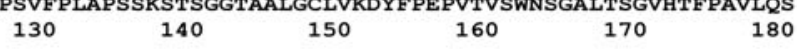

$\begin{array}{llllll}180 & 190 & 200 & 210 & 220 & 230\end{array}$

Trastu SGLYSLSSVVTVPSSLGTQTYICNVNHKPSNTKVDKKVEPKSCDKTHTCPPCPAPELLG $:::::::::::::::::::::::::::::::::::::::::::::::::::::::::::::$ : Adalim SGLYSLSSVVTVPSSLGTQTYICNVNHKPSNTKVDKKVEPKSCDKTHTCPPCPAPELLG

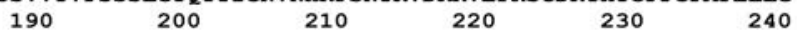


Figure S4. ESI mass spectra for the $\mathrm{Fc} / 2$, Lc, and $\mathrm{Fd}$ subunits of trastuzumab (a-c) and adalimumab (d-f), respectively, collected at $120 \mathrm{~K}$ resolution (at $\mathrm{m} / \mathrm{z} 400$ ). The insets for the $\mathrm{Fc} / 2$ subdomains demonstrate the glycoform heterogeneity in each $\operatorname{IgG}$ based on accurate mass measurement. Trastuzumab exhibited the G0, G0F, G1F, and G2F glycoforms (a), whereas adalimumab exhibited the G0F and G1F variants only. The insets for all other subunits demonstrate the isotope distribution for the most abundant charge state.

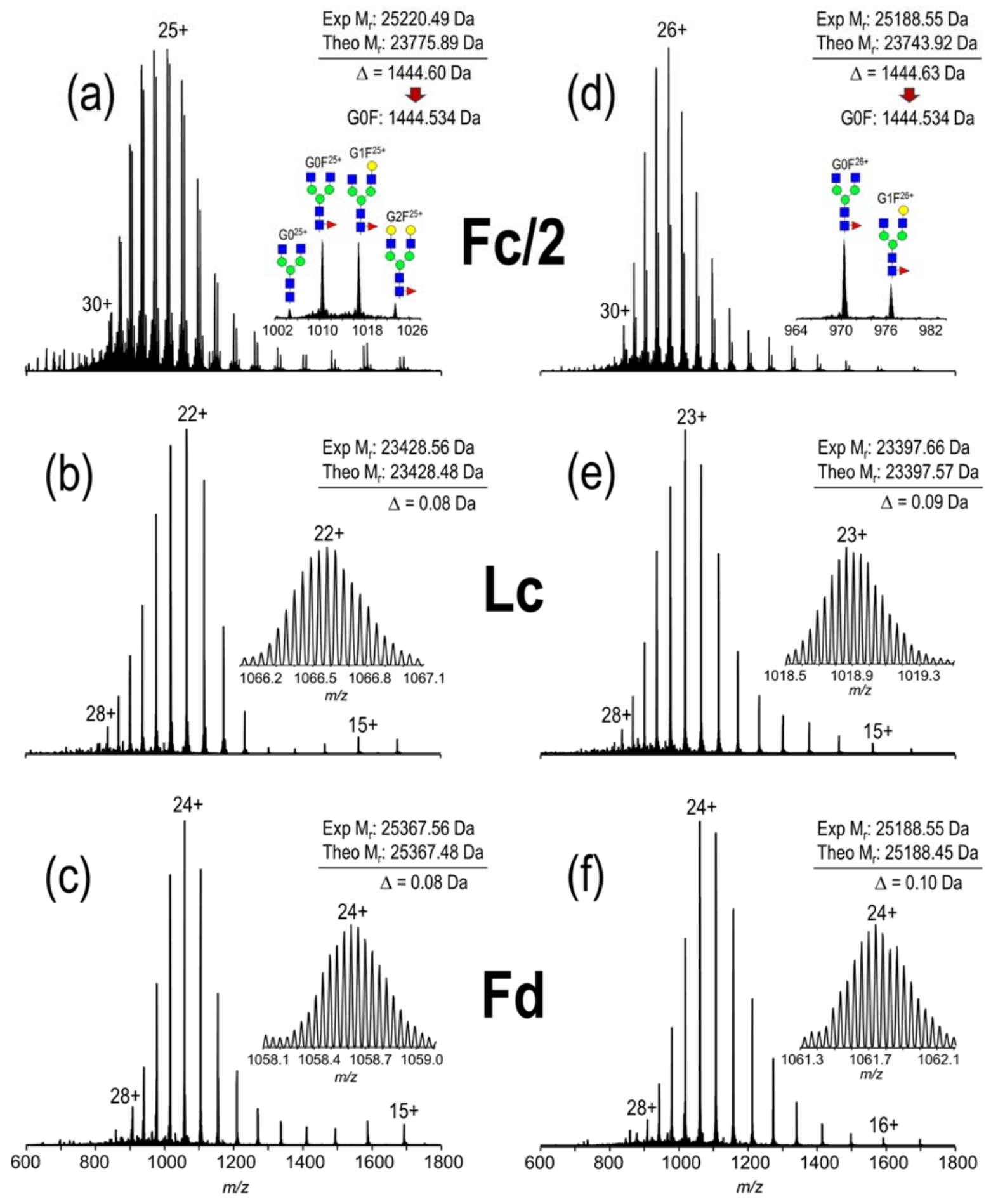


Figure S5. Sequence coverage observed as a function of laser parameter selection used for targeted UVPD of the most abundant precursor of the Fc/2 (25+), Lc (22+) and $\mathrm{Fd}(24+)$ subunits of trastuzumab.

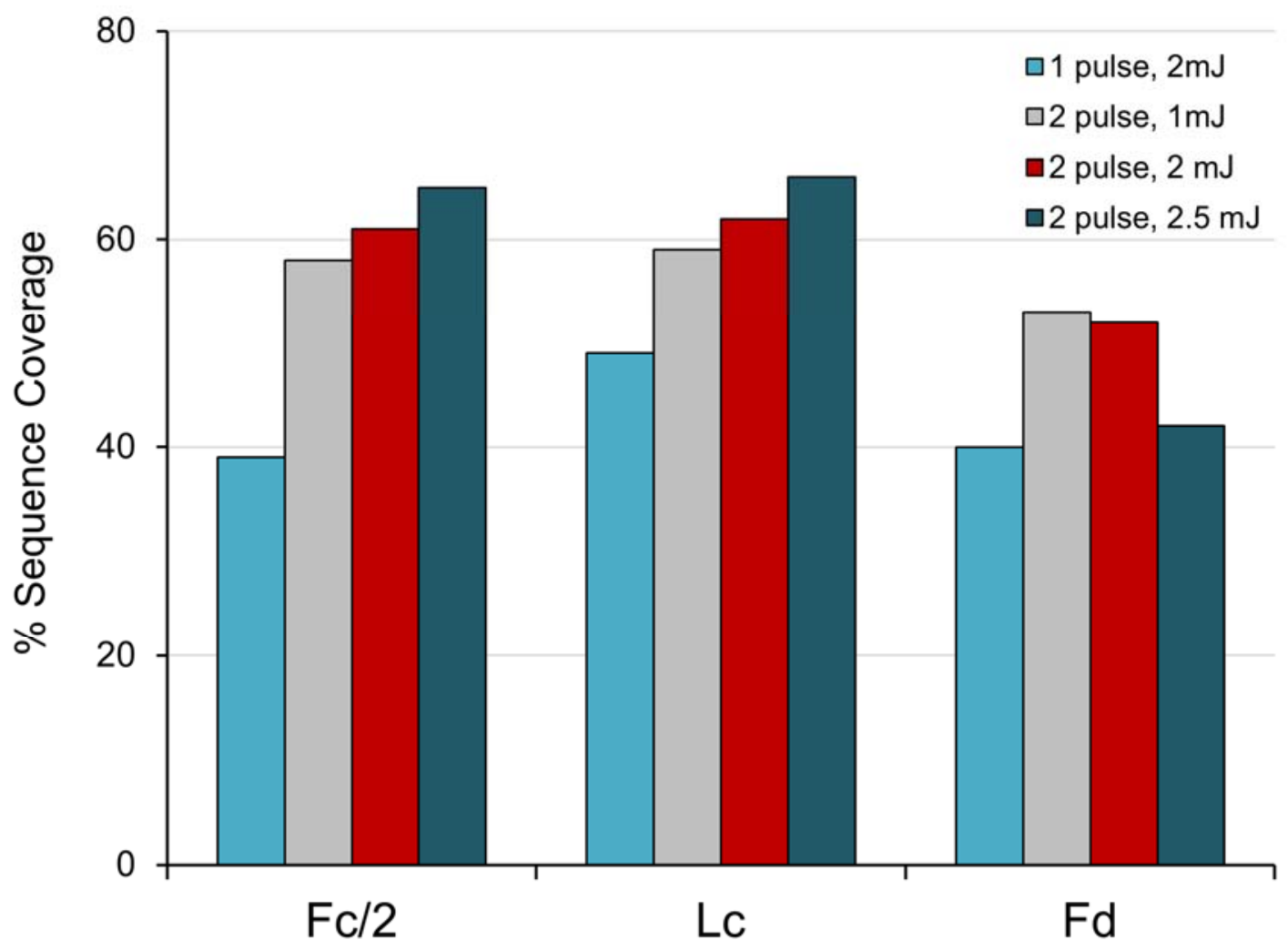


Figure S6. Evaluation of unique fragment ions and sequence coverage obtained from a targeted LC-MS/MS analysis of adalimumab subunits based on UVPD $(20 \mathrm{~m} / \mathrm{z}$ isolation, most abundant charge state), ETD (5 ms reaction time) using single precursor isolation $(20 \mathrm{~m} / \mathrm{z}$ isolation, the most abundant charge state), and ETD ( $5 \mathrm{~ms}$ reaction time) using multiple precursor isolation $(150 \mathrm{~m} / \mathrm{z}$ isolation, high charge states). The most abundant charge states were as follows: +26 for $\mathrm{Fc} / 2,+23$ for Lc, and +24 for Fd. The isolation range used for multiple precursor isolation included: +26 to +30 for $\mathrm{Fc} / 2,+25$ to +27 for Lc, and +25 to +28 for Fd. The fourth bar (shaded purple) in the second bar graph shows the net sequence coverage for combined product ion information from UVPD and broadband ETD.
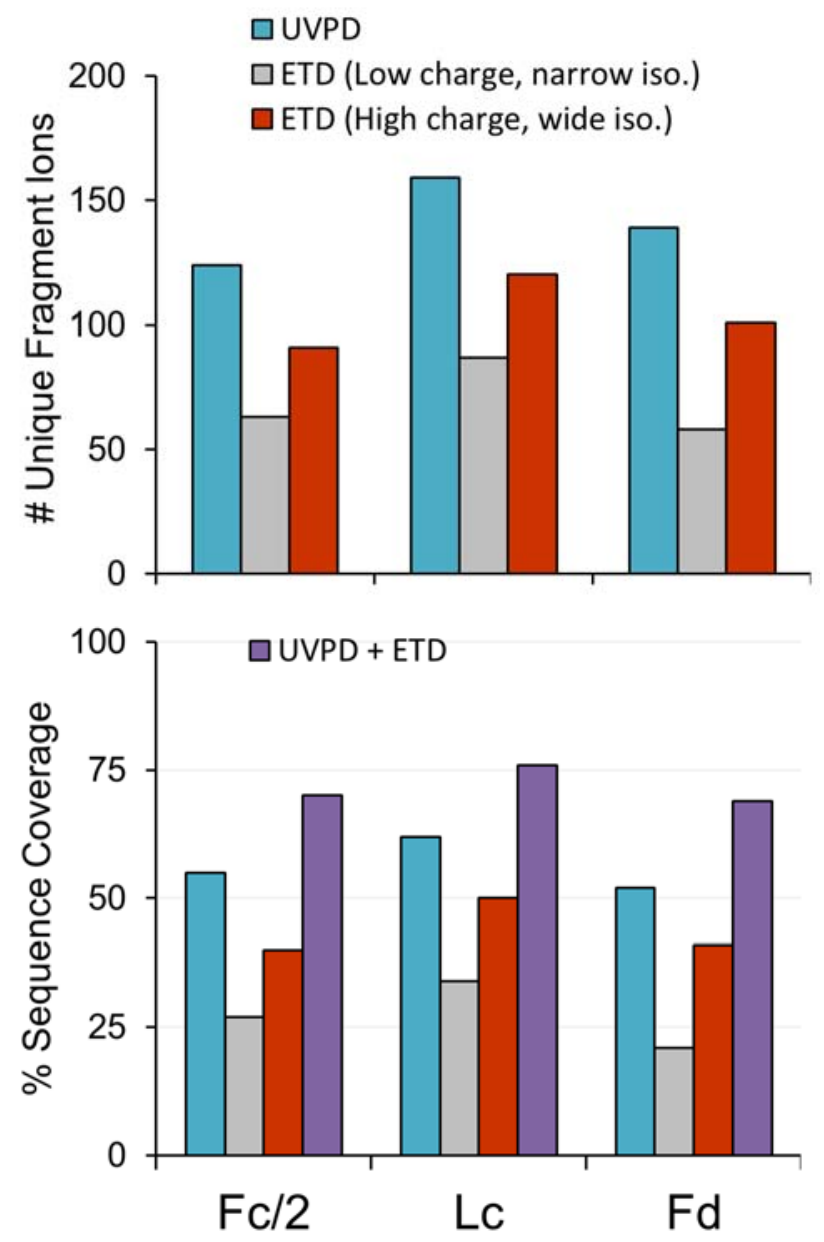
Figure S7. Fragment ion maps for the Fc/2 subunit of trastuzumab generated by a single LCMS/MS experiment based on UVPD (top left) and broadband ETD (top right) and a composite map (bottom) generated by combining the fragment ion information from both experiments.

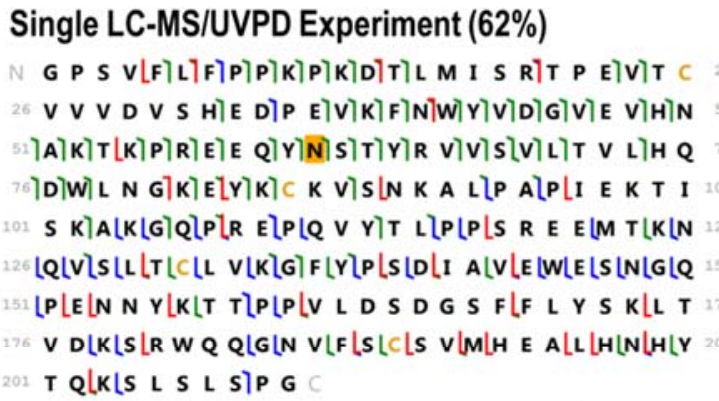

.

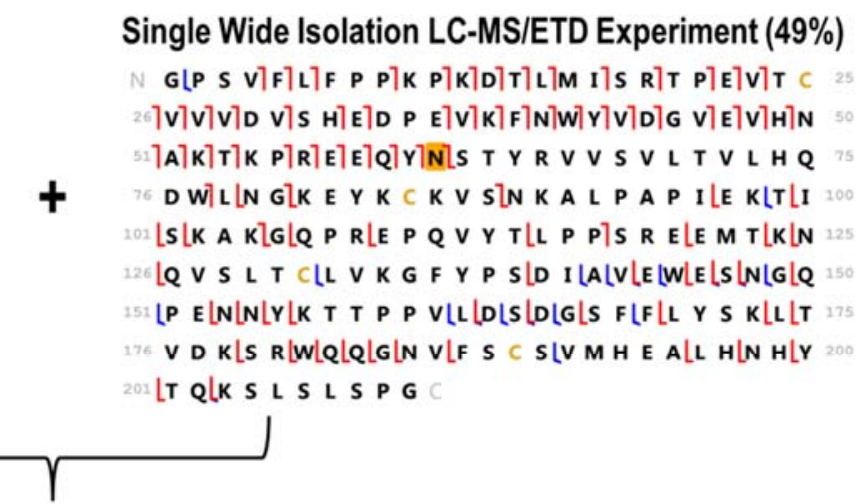

\footnotetext{
Combined lon Information from UVPD + ETD $(79 \%)$

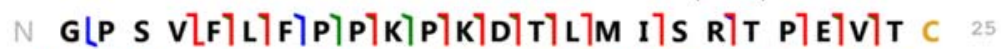

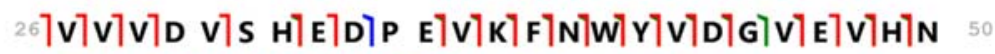

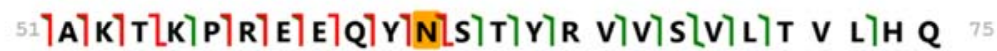

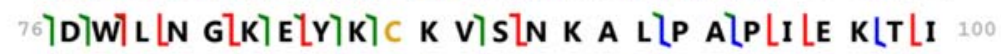

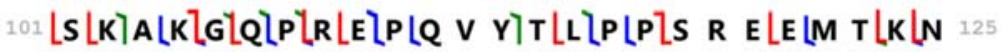

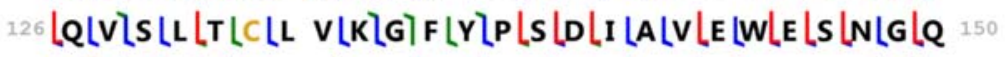

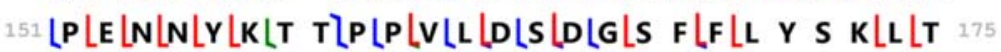

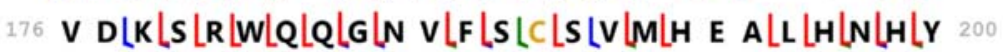

${ }^{201}$ LT QLKLS L S L S TP G C
} 
Figure S8. Zoomed-in view of spectral region spanning from $880-900 \mathrm{~m} / \mathrm{z}$ for Fd subunit of trastuzumab following isolation of the most abundant precursor ion (24+) obtained using (a) UVPD ( 2 pulses, $2 \mathrm{~mJ}$ ) and (b) ETD ( $5 \mathrm{~ms}$ reaction time), respectively, and (c) ETD (5 ms reaction time) with wide isolation $(150 \mathrm{~m} / \mathrm{z})$ centered at the $27+$ charge state.

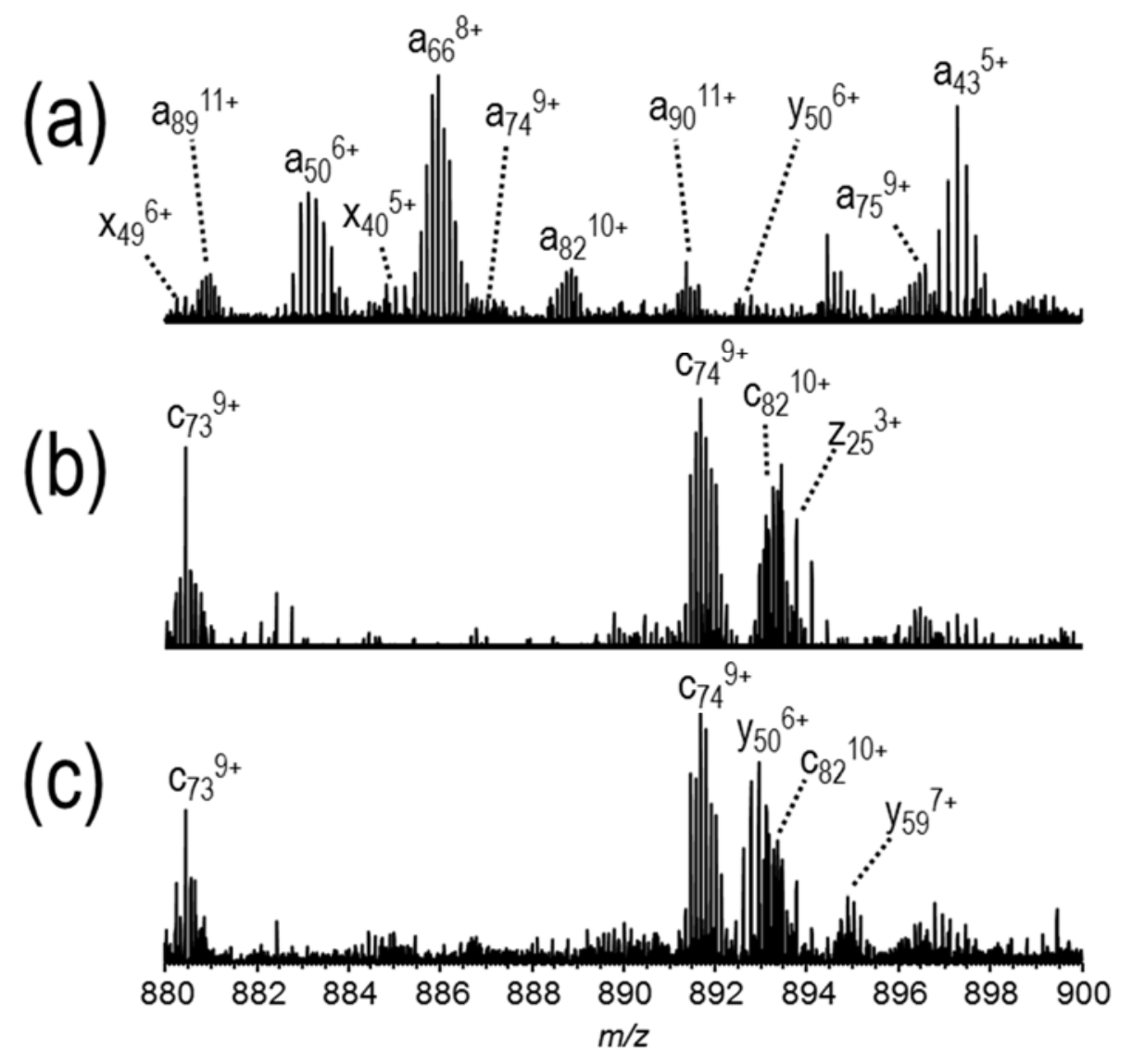


Table S1. List of confidently identified fragment ions (10 ppm mass tolerance, $\mathrm{S} / \mathrm{N} \geq 3$ ) for the Fc/2 (Sheet 1), Lc (Sheet 2), and Fd (Sheet 3) subunits of trastuzumab using: UVPD (20 m/z isolation, most abundant charge state), ETD ( $5 \mathrm{~ms}$ reaction time) using single precursor isolation ( $20 \mathrm{~m} / \mathrm{z}$ isolation, the most abundant charge state), and ETD (5 ms reaction time) using multiple precursor isolation (150 Th isolation, high charge states). The most abundant charge states were as follows: +25 for $\mathrm{Fc} / 2$, +22 for $\mathrm{Lc}$, and +24 for $\mathrm{Fd}$. The isolation range used for multiple precursor isolation included: +25 to +31 for $\mathrm{Fc} / 2,+24$ to +28 for $\mathrm{Lc}$, and +25 to +29 for $\mathrm{Fd}$.

Table S2. List of confidently identified fragment ions (10 ppm mass tolerance, $\mathrm{S} / \mathrm{N} \geq 3$ ) for the Fc/2 (Sheet 1), Lc (Sheet 2), and Fd (Sheet 3) subunits of adalimumab using: UVPD (20 m/z isolation, most abundant charge state), ETD (5 ms reaction time) using single precursor isolation ( $20 \mathrm{~m} / \mathrm{z}$ isolation, the most abundant charge state), and ETD (5 ms reaction time) using multiple precursor isolation (150 Th isolation, high charge states). most abundant charge states were as follows: +26 for $\mathrm{Fc} / 2,+23$ for $\mathrm{Lc}$, and +24 for $\mathrm{Fd}$. The isolation range used for multiple precursor isolation included: +26 to +30 for $\mathrm{Fc} / 2,+25$ to +27 for $\mathrm{Lc}$, and +25 to +28 for $\mathrm{Fd}$. 